\title{
THE IMPACT ANALYSIS OF CURRENT HUMAN RESOURCE MANAGEMENT ISSUES TOWARD MOTIVATION FUNCTION: OUTSOURCING, MERGERS-ACQUISITIONS, AND CONTRACTUAL WORKERS
}

\author{
Rony Setiawan \\ Henky Lisan Suwarno \\ Universitas Kristen Maranatha Bandung
}

\begin{abstract}
Three main issues which growing in Indonesia in the field of human resource management is: outsourcing, mergers-acquisitions, and contractual workers. These issues affect on job insecurity among workers in company. Job insecurity can decrease workers performance directly and company performance indirectly. Authors describe the practice of those issues in several companies in service industries. Authors give recommendation that organization should manage those issues by concern on motivation function through extrinsic and intrinsic motivation.
\end{abstract}

Keywords: outsourcing, mergers-acquisitions, contractual workers, job insecurity, motivation functions.

\section{INTRODUCTION}

Nowadays, companies in Indonesia are faced by the entry of foreign companies. For that, local and national companies not only compete with the similar companies, but also with the companies which comes from abroad. This phenomenon resulted high tension of business competition in Indonesia. With this situation the companies are forced to manage their activities as effective and efficient as possible to survive even win the competition. Like a proverb says "Many ways to Rome", the companies have several alternative strategies to reach it. One of companies' actions that can be implemented is outsourcing, mergersacquisition and hires contractual workers. These three strategies contribute positive impact to companies.

Outsourcing has several advantages. First is cost saving, outsourcing is lowering the overall cost of the service to the business. Second is improve quality, achieve a step change in quality through contracting out the service with a new service level agreement. Third is knowledge, outsourcing makes access to intellectual property and wider experience and knowledge. Fourth is contract, services will be provided to a legally binding contract with financial penalties and legal redress. Fifth is operational expertise, outsourcing creates access to operational best practice that would be too difficult or time consuming to develop in-house. Sixth is staffing issues, outsourcing creates access to a larger talent pool and a sustainable source of skills. Seventh, capacity management, outsourcing creates an improved method of capacity management of services and technology where the risk in providing the excess capacity is borne by the supplier. Eighth is catalyst for change, an 
organization can use an outsourcing agreement as a catalyst for major step change that cannot be achieved alone where the outsourcer becomes a change agent in the process. Ninth is reduce time to market, outsourcing enables the acceleration of the development or production of a product through the additional capability brought by the supplier. Tenth, commodification, outsourcing allows a wide range of businesses access to services previously only available to large corporations. Eleventh, risk management, outsourcing becomes an approach to risk management for some types of risks is to partner with an outsourcer who is better able to provide the mitigation.

Mergers and acquisitions have several advantages. First is synergy. This refers to the fact that the combined company can often reduce duplicate departments or operations, lowering the costs of the company relative to the same revenue stream, thus increasing profit. Second is increased revenue/increased market share. The company will be absorbing a major competitor and thus increase its power (by capturing increased market share) to set prices. Third is, cross selling, for example, a bank buying a stock broker could then sell its banking products to the stock broker's customers, while the broker can sign up the bank's customers for brokerage accounts; or, a manufacturer can acquire and sell complementary products. Fourth is economies of scale, for example, managerial economies such as the increased opportunity of managerial specialization; another example is purchasing economies due to increased order size and associated bulk-buying discounts. Fifth, are taxes, a profitable company can buy a loss maker to use the target's loss as their advantage by reducing their tax liability. Sixth is geographical or other diversification, this is designed to smooth the earnings results of a company, which over the long term smoothens the stock price of a company, giving conservative investors more confidence in investing in the company. Seventh, resource transfer, resources are unevenly distributed across firms (Barney, 1991) and the interaction of target and acquiring firm resources can create value through either overcoming information asymmetry or by combining scarce resources.

Using contractual workers has several advantages. First, easy hire, those meeting technical requirements for the type of work are often virtually guaranteed a job without a selection process. Second, flexible hours; a choice of which shifts to work; the ability to take off for weekends, holidays, vacations, personal appointments, or for any other reason of choice, or to work on such days for additional pay. Third is pay rates are often higher than the customary wages in a comparable permanent position. Fourth is the likelihood of getting fired is lower than in a permanent position, though a client of the agency can make a request for the temporary worker not to return, even for a minor infraction.

Thus, these three strategies, conduct outsourcing, mergers-acquisitions and use contractual workers will give very valuable benefits to the companies in one hand. But, they 
like a coin which has two sides. In the other hand, these strategies can bring negative impact to pertinent workers, job insecurity. Job insecurity will push the workers to show negative bad attitudes and behavior which can affect negatively to job performance and company performance entirely. These circumstances become the importance's background of outsourcing, mergers-acquisitions, and contractual workers. The authors limit the scope of this article only on the impact of those issues on workers' attitudes and behaviors, especially job insecurity.

\section{ISSUES' CONCEPTS}

In this section, the authors explain the concept of outsourcing, mergers-acquisitions and contractual workers. Then, explain the impact of those issues on job insecurity conceptually. Moreover, the authors describe the phenomenon of this problem through business practices, especially human resources in Indonesia.

\section{Outsourcing}

Outsourcing is subcontracting a process, such as product design or manufacturing, to a third-party company. The decision to outsource is often made in the interest of lowering firm costs, redirecting or conserving energy directed at the competencies of a particular business, or to make more efficient use of land, labor, capital, (information) technology and resources. Outsourcing became part of the business lexicon during the 1980s.

Outsourcing involves the transfer of the management and/or day-to-day execution of an entire business function to an external service provider. The client organization and the supplier enter into a contractual agreement that defines the transferred services. Under the agreement the supplier acquires the means of production in the form of a transfer of people, assets and other resources from the client. The client agrees to procure the services from the supplier for the term of the contract. Business segments typically outsourced include information technology, human resources, facilities, real estate management, and accounting. Many companies also outsource customer support and call center functions like telemarketing, cad drafting, customer service, market research, manufacturing, designing, web development, content writing, ghostwriting and engineering.

Outsourcing and off shoring are used interchangeably in public discourse despite important technical differences. Outsourcing involves contracting with a supplier, which may or may not involve some degree of off shoring. Off shoring is the transfer of an organizational function to another country, regardless of whether the work is outsourced or stays within the same corporation/company.

With increasing globalization of outsourcing companies, the distinction between outsourcing and off shoring will become less clear over time. This is evident in the increasing 
presence of Indian outsourcing companies in the US and UK. The globalization of outsourcing operating models has resulted in new terms such as near shoring, no shoring, and right shoring that reflect the changing mix of locations. This is seen in the opening of offices and operations centers by Indian companies in the U.S. and UK.

Multi outsourcing refers to large (predominantly IT) outsourcing agreements. Multi outsourcing is a framework to enable different parts of the client business to be sourced from different suppliers. This requires a governance model that communicates strategy, clearly defines responsibility and has end-to-end integration.

Strategic outsourcing is the organizing arrangement that emerges when firms rely on intermediate markets to provide specialized capabilities that supplement existing capabilities deployed along a firm's value chain (see Holcomb \& Hitt, 2007). Such an arrangement produces value within firms' supply chains beyond those benefits achieved through cost economies. Intermediate markets that provide specialized capabilities emerge as different industry conditions intensify the partitioning of production. As a result of greater information standardization and simplified coordination, clear administrative demarcations emerge along a value chain. Partitioning of intermediate markets occurs as the coordination of production across a value chain is simplified and as information becomes standardized, making it easier to transfer activities across boundaries.

\section{Mergers-Acquisitions}

The phrase mergers and acquisitions (abbreviated M\&A) refers to the aspect of corporate strategy, corporate finance and management dealing with the buying, selling and combining of different companies that can aid, finance, or help a growing company in a given industry grow rapidly without having to create another business entity.

A merger is a tool used by companies for the purpose of expanding their operations often aiming at an increase of their long term profitability. There are 15 different types of actions that a company can take when deciding to move forward using M\&A. Usually mergers occur in a consensual (occurring by mutual consent) setting where executives from the target company help those from the purchaser in a due diligence process to ensure that the deal is beneficial to both parties. Acquisitions can also happen through a hostile takeover by purchasing the majority of outstanding shares of a company in the open market against the wishes of the target's board. In the United States, business laws vary from state to state whereby some companies have limited protection against hostile takeovers. One form of protection against a hostile takeover is the shareholder rights plan, otherwise known as the "poison pill".

Historically, mergers have often failed (Straub, 2007) to add significantly to the value of the acquiring firm's shares (King, et al., 2004). Corporate mergers may be aimed at 
reducing market competition, cutting costs (for example, laying off employees, operating at a more technologically efficient scale, etc.), reducing taxes, removing management, "empire building" by the acquiring managers, or other purposes which may or may not be consistent with public policy or public welfare.

An acquisition, also known as a takeover, is the buying of one company (the 'target') by another. An acquisition may be friendly or hostile. In the former case, the companies cooperate in negotiations; in the latter case, the takeover target is unwilling to be bought or the target's board has no prior knowledge of the offer. Acquisition usually refers to a purchase of a smaller firm by a larger one. Sometimes, however, a smaller firm will acquire management control of a larger or longer established company and keep its name for the combined entity. This is known as a reverse takeover.

In business or economics a merger is a combination of two companies into one larger company. Such actions are commonly voluntary and involve stock swap or cash payment to the target. Stock swap is often used as it allows the shareholders of the two companies to share the risk involved in the deal. A merger can resemble a takeover but result in a new company name (often combining the names of the original companies) and in new branding; in some cases, terming the combination a "merger" rather than an acquisition is done purely for political or marketing reasons.

Although they are often uttered in the same breath and used as though they were synonymous, the terms merger and acquisition mean slightly different things.

When one company takes over another and clearly established itself as the new owner, the purchase is called an acquisition. From a legal point of view, the target company ceases to exist, the buyer "swallows" the business and the buyer's stock continues to be traded.

In the pure sense of the term, a merger happens when two firms, often of about the same size, agree to go forward as a single new company rather than remain separately owned and operated. This kind of action is more precisely referred to as a "merger of equals". Both companies' stocks are surrendered and new company stock is issued in its place. For example, both Daimler-Benz and Chrysler ceased to exist when the two firms merged, and a new company, DaimlerChrysler, was created.

In practice, however, actual mergers of equals don't happen very often. Usually, one company will buy another and, as part of the deal's terms, simply allow the acquired firm to proclaim that the action is a merger of equals, even if it is technically an acquisition. Being bought out often carries negative connotations, therefore, by describing the deal euphemistically as a merger, deal makers and top managers try to make the takeover more palatable. 
A purchase deal will also be called a merger when both CEOs agree that joining together is in the best interest of both of their companies. But when the deal is unfriendly that is, when the target company does not want to be purchased - it is always regarded as an acquisition.

Whether a purchase is considered a merger or an acquisition really depends on whether the purchase is friendly or hostile and how it is announced. In other words, the real difference lies in how the purchase is communicated to and received by the target company's board of directors, employees and shareholders. It is quite normal though for M\&A deal communications to take place in a so called 'confidentiality bubble' whereby information flows are restricted due to confidentiality agreements (Harwood, 2006).

A study published in the July/August 2008 issue of the Journal of Business Strategy suggests that mergers and acquisitions destroy leadership continuity in target companies' top management teams for at least a decade following a deal. The study found that target companies lose 21 percent of their executives each year for at least 10 years following an acquisition - more than double the turnover experienced in non-merged firms.

\section{Contractual Workers}

Contractual work or contractual employment refers to a situation where the employee is expected to leave the employer within a certain period of time. Contractual employees are sometimes called "temporary" or "seasonal" or "freelance" or "temps." Agricultural workers are often temporarily employed for harvesting. In some instances, contractual professional employees (particularly in the white collar fields, such as law, engineering, and accounting) even refer to themselves as "consultants." This is not to be confused with management consultants who are salaried employees of major consulting firms (e.g. McKinsey \& Company, The Boston Consulting Group).

They may work full-time or part-time, depending on the individual case. In some instances, they are given benefits (such as health insurance), but usually the best treatment is reserved for the permanent employees. It is important to note that not all temporary employees find jobs through a contractual Employment agency. For example, a person can simply apply at a local park for seasonal jobs.

A contractual work agency, or temp agency or temporary staffing firm finds and retains workers. Other companies, in need of short-term workers, contract with the temp agency to send contractual workers, or temps, on assignment to work at the other companies. Contractual employees are also used in work that has a cyclical nature that requires frequent adjustment of staffing levels. 
A contractual agency may be distinct from a recruitment firm, which seeks to place permanent employees, but there is often a large overlap: a permanent employee may start out as a "try-before-you-buy" trial contractual worker.

Many contractual agencies specialize in a particular profession or field of business, such as general industrial labor, accounting, health care, technical or secretarial. Some even "specialize" in odd-jobs. Because of the added level of communication between the employer (worksite) and the contractual agency and then finally to the agency's employee these short-term roles can be miscommunicated and cancelled on a whim. The employer (worksite) is paying for a service and can decide to stop that service (labor/skills) at any time.

A contractual agency may have a standard set of tests to judge the competence of the secretarial or clerical skills of an applicant. An applicant is hired based on their scores on these tests, and is placed into a database. Companies or individuals looking to hire someone temporarily contact the agency and describe the skill set they are seeking. A contractual employee is then found in the database and is contacted to see if they would be interested in taking the assignment.

When a contractual employee agrees to take on an assignment, he or she receives instructions pertaining to the job. Information is provided on the correct attire to wear, hours of work, the wage to be paid, and who to report to upon arriving. If a contractual employee arrives at a job assignment and is asked to perform duties not described to him or her when accepting the job, he or she is expected to call the agency and speak with a representative. If he or she then chooses not to continue on the assignment based on these discrepancies, they will most likely be subject to loss of pay and will undermine their chances of job opportunities. However, some agencies will guarantee an employee a certain number of hours pay if, once the contractual employee arrives, there is no work or the work isn't as described. Most agencies will not require an employee to continue work if the discrepancies are enough to make it difficult for the employee to actually do the work.

It is up to the contractual employee to keep in constant contact with the agency when not currently working on an assignment; by letting the agency know that they are available to work they are given priority over those who may be in the agency database who have not made it clear that they are ready and willing to take an assignment. A contractual agency employee is the exclusive employee of the agency, not of the company in which they are placed (although subject to legal dispute). The contractual employee is bound by the rules and regulations of their direct employer, even if they contrast with those of the company in which they are placed. For example, if a contractual employee is asked by the company in which they are placed to lift a heavy box, they may 
respond "I am sorry, my agency does not allow me to perform that task. I wish I could help. Please feel free to contact my supervisor there for more information."

Contractual employees are in a constant state of employment flux because they are never guaranteed consistent employment, nor are they assured of a solid start or finish date for their assignment. A contractual employee's assignment can be ended at any time, even in the middle of its projected time frame, without explanation. This causes potential turbulence in cases of discrimination, which is usually handled internally between the employee and the agency.

\section{Job Insecurity}

Greenhalgh and Rosenblatt (1984, in Ashford et al., 1989) conceptualized job insecurity as a source of stress involving fear, potential loss, and anxiety. One outcome of such stress is strain in the form of somatic complaints like lack of sleep, dizziness, and loss of appetite. Taber, Walsh, and Cooke (1979, in Ashford et al., 1989) suggested that strain from perceived job insecurity can increase somatic complaints and hypertension. Popular accounts of major organizational changes have also cited strain-related complaints as an outcome of insecurity engendered by transition periods (cf. Ackerman, 1982, in Ashford et al., 1989). Such outcomes are not only important from a humanitarian perspective, but also place real financial burdens on firms in the form of health-care costs and absenteeism (Matteson \& Ivancevich, 1987, in Ashford et al., 1989). Since firm often must bear stressrelated health costs, the relationship between job insecurity and somatic complaints is practically, as well as theoretically important.

Strains induced by job insecurity are also important because of their effects on turnover. Like any stressor, job insecurity may be related to a withdrawal response - an attempt to avoid the stress altogether. Thus, job insecurity should have a positive relationship to intentions to quit (Arnold \& Feldman, 1982; Smith \& Kerr, 1953; Stogdill, 1965, in Ashford et al., 1989).

People experiencing job insecurity may also leave for rational reasons - it would be rational for employees worried about continuity of employment to seek more secure career opportunities (Greenhalgh \& Rosenblatt, 1984; 443, in Ashford et al., 1989). Thus, whether they are experiencing strains or not, employees who can easily find employment elsewhere might be expected to react to situations that induce insecurity by seeking new jobs. Indeed, turnover - particularly among high performers - is a primary reason for organizational concern about job insecurity.

Research has also indicated that people develop affective and attitudinal attachments to firms over time (Mowday, Steers, \& Porter, 1979, in Ashford et al., 1989), which shows up as high levels of commitment, satisfaction, and trust. Feelings of job insecurity may 
threaten such basis attachments to a firm. Employees count on organizations to dependably uphold their end of the psychological contract between them (cf. Buchanan, 1974, in Ashford et al., 1989). Perceived job insecurity may reflect an individual's perception that a firm has abrogated the psychological contract - important features seem threatened, the job itself seems at risks, or both. Loyalty should consequently be negatively affected (Romzek, 1985, in Ashford et al., 1989).

Steers (1977, in Ashford et al., 1989) presented evidence consistent with this perspective. Individuals who perceived their organizations to be undependable in carrying out their commitments to employees were, in turn, less committed to their organizations. We hypothesized that job insecurity would be negatively related to both employees' commitment and their trust in a firm (Forbes, 1985, in Ashford et al., 1989). These relationships occur primarily because insecure employees lose faith in the dependability of organizations, and their attachment to the firms may diminish accordingly. Such employees may also become more self-interested (Freedman, 1986; Romzek, 1985; Rosow \& Zager, 1985, in Ashford et al., 1989).

Perceptions of job insecurity should be negatively associated with measures of job satisfaction. One previous study (Oldham, Julik, Ambrose, Stepina, \& Brand, 1986, in Ashford et al., 1989) found that employees with lower perceptions of job security than various comparison referents (including themselves at previous times) were less satisfied with their job than were their referents. We hoped to replicate that finding with new measure of job insecurity. Researches have typically defined job satisfaction as an affective response to job and task events (Locke, 1969). People respond affectively to jobs in terms of how they cognitively represent or perceive the jobs (Hackman \& Oldham, 1976, in Ashford et al., 1989). To the extent that job insecurity represents a constellation of perceptions regarding possible negative task events, it will be likely to have a negative effect on job satisfaction as the primary affective response to a job.

The definition of job insecurity has taken many forms and has been extended in recent years to include not only the anxiety of losing one's job but also the change of work roles and job features. Mauno et al. (2001), in Canaff and Wright (2004) included the loss of job features, such as potential job transfer, in their definition of job insecurity. Greenhalgh and Rosenblatt (1984) in Canaff and Wright (2004), defined job insecurity as "perceived powerlessness to maintain desired continuity in a threatened job situation". Ashford, lee, and Bobko (1989) in Canaff and Wright (2004) viewed job insecurity in a comprehensive manner that includes (a) degree of severity of threat to one's job and aspects of the work, (b) importance of the threatened job feature, (c) the negative effect of perceived threats on the entirely of the work situation, (d) the total of the aforementioned, and (e) subjective 
sense of powerlessness. Lim (1997) in Canaff and Wright (2004) founded that job insecurity as work stressor that results in detrimental job attitudes and behaviors.

Those above issues have impact on job insecurity. The common motives of outsourcing is the company think that the worker who outsourced from outside of the company can help some of the company activities which can't finished by the inside workers; or by outsourcing company can spend less of money which paid for the human power. This situation perceived by the workers who working in the company as the doubt of the company toward their capability. In the long term, means that outsourcing become company culture, the worker will feel that their existence and utilization of their effort can be substituted by outsource workers. Or in the other word, their working continuity in the company is threatened and uncertainty created. Finally, this condition resulted in job insecurity. Merger and acquisition ( $M$ \& A) create a new company, especially job design, worker composition and company culture. $M$ \& A can be viewed as invisible downsizing means that in this strategy contain the high possibility of worker lay off. The new company which is the product of $M$ \& A can't use all workers from the incumbent company because of the efficiency. This condition forced the company to reduce worker's amount. It can make the incumbent company worker have high of anxiety if they will be laid off by the new company. They will be sure that they can out involuntary from the new company on every time in the future. Finally, this condition resulted in job insecurity. Contractual workers are the workers who their working period time limited by the contract between the workers and the company. It means that the working continuity of the contractual worker is depending on the contract and its extension time. The decision to extent in using the contractual workers depends on the company need and willingness. It can be said that they have less power to exist in the company. Every time the company can decide to cut contractual relationship with the contractual worker by themselves. Finally, this condition resulted in job insecurity.

These relationships among outsourcing, $M \& A$, contractual workers and job insecurity are supported by the empirical evidence as following. The $2006 \mathrm{CMI}$ (Chartered Management Instituted) survey toward many UK and European companies, found that $63 \%$ of managers at all levels reported that their organization was engaged in a substantial cost reduction programs, 57\% reported the use of short-term contract staff, $36 \%$ reported a major redundancy programs, and $25 \%$ said there was substantial outsourcing. Managers felt that this constant change, and the underlying breaking of the psychological contract between employer and employee by these activities, led to declining motivation (57\%), reduced sense of job security $(66 \%)$, poorer morale $(61 \%)$, poorer employee well-being (48\%) and decreased loyalty to the organization (47\%). The study which conducted in a large firm involved in both research and development, and manufacturing toward employees who 
chosen randomly from the population through completed survey questionnaires on company time on two occasions (before and after $M$ \& A); show that job insecurity increase from 2.07 to 2.30 . It means that $M \& A$ have positive impact on job insecurity.

\section{Phenomenon of outsourcing, mergers-acquisitions, and contractual workers in Indonesia}

- About 1.200 contractual workers of Exxon Mobil were go on strike. As reaction toward its company management decision which will conduct layoffs toward 1.300 contractual workers. There are about 3.000 contractual workers in this oil and gas company. It was happened because the previous meeting between management and worker's parties wasn't reach a deal. Exxon Mobil, a company which came from USA will continually conduct layoff because working contractual period regarded to be finished and the reduce of natural gases reserves which lead to efficiency effort, as the motive. There was a different perception between Exxon Mobil and contractual workers. In one side, the company viewed that this management decision as the nature of ending contract period; in the other side, the workers viewed that this management decision as layoffs toward contractual workers.

- Hundreds of contractual and honorary workers of PDAM in Surabaya conduct demonstration in front of its office. It was happen because the leadership style of main director of PDAM assessed arrogant. In run the company, that main director often got complains from the workers, include the layoffs policy toward about 73 contractual and honorary workers. This policy makes other contractual and honorary workers become anxious. This situation was worsened with the recruitment of 100 new contractual workers.

- Pertamina had layoffs 162 contractual workers in Indonesia. It was happened because Pertamina refuse to extend contract period according to the decision letter about the ending of contract settlement case. But, in other side the worker's representative regard that company decision conduct layoffs wasn't fit to the procedure. The company was conducted layoffs partly without the agreement of labor department.

- Mergers among Bank Eksim, BDN, BBD, and Bapindo became Bank Mandiri which started on Oktober 1998. Previously number of workers in those four bank are 26.609 people, then after mergers that number decrease amounting to 15.914 people. Its mean that there was a reduction of worker's number. This condition creates "the followers". One of them is unification among Bank Universal, Bank Bali, Bank Prima Express, Bank Media, and Bank Patriot became Bank Permata. Finally, all of these resulted on unemployment.

- PT. Nutricia Indonesia Sejahtera has been six years used outsourced workers. The management practices viewed that until now the outsourcing power actually help enough in company wheel process. The nature of this outsourcing is supporting the company's business performance. PT Nutricia thought that the quality of outsourced 
workers must be reached and maintained, in order to reach maximum satisfaction in using them. The quality of outsourced workers is seemed from ability, working quality, and discipline. To make this situation achieved, PT Nutricia provides training to develop the outsourced workers quality. Outsourced workers regarded as the workers who have specialized competency which positively contribute to PT. Nutricia.

\section{RECOMMENDATION \& CONCLUSION}

Conceptually, outsourcing, mergers-acquisitions, and contractual workers can cause the emergence of job insecurity. The authors have recommendation to solve this problem based on human resource management functions. There are four main functions of human resource management: acquisition function (recruitment, selection, and placement, and human resource planning), development function (training programs and management training), maintenance function (any government regulations about human resources and working conditions), and motivation function (compensation and benefits system, rewards and incentives programs, performance evaluation). Among these four functions, the authors focused on motivation function as the "wise answer" for minimize bad effect of those issues or even resolved them.

According to Herzberg theory, there are two types of motivations, extrinsic and intrinsic. Extrinsic motivation related to any aspects which can push workers to perform well by physical motivation tools, such as money in form of compensation. Intrinsic motivation related to any aspects which can push workers to perform well by psychological motivation tools, such as recognition, advancement, and achievement.

Job insecurity can be perceived as unmotivated excellent performance of workers; because it is stimulated from anxiety of workers towards uncomfortable working conditions. The workers who live in unfriendly working environment in the company will feel confuse, lazy; have negative perception about the future trend of their jobs and their organization; and further doesn't want to achieve optimum job performance. They will react toward this condition through a tendency of bad attitudes (invisible) and behave in negative actions (visible, in real). Based on these interrelationships, the authors take motivation both extrinsic and intrinsic to grow up workers' motivation which will help to achieve decreased job insecurity.

Motivation the act of giving somebody a reason or incentive to do something; a feeling of enthusiasm, interest, or commitment that makes somebody wants to do something, 
or something that causes such a feeling; or a reason for doing something or behaving in a particular way. In short, motivation can be defined as something which comes from intern of somebody which encourages somebody to do something. Motivation can be regarded as significant human resource tools to cure job insecurity among workers; because motivation will directly strengthens the workers feel and the way of thinking about their jobs and organizations. Motivation will change their negative paradigm which caused b y job insecurity that they don't have power to arrange and determine their sustainability in their jobs and organizations. Motivation will makes the workers have a positive expectation and spirit which will be implied in actual actions; they will motivated to regard themselves as an valuable asset and can determine the good future of their jobs in the organization.

As one of the important human resources integrated part in every companies, motivation function consist of compensation and benefits system, rewards and incentives programs, performance evaluation. If related with Herzberg two factors theory, motivation functions consists of two main kinds: extrinsic (compensation) and intrinsic (performance evaluation) motivation. As explained in previous section of this article, extrinsic motivation is physical things which can motivated someone to do something good, better, or even the best toward their jobs. Different with that, intrinsic motivation is more psychological things, invisible but felt on the effect of its implementation.

Compensation is one form of intrinsic motivation. Compensation is financials or non financials return which given to the workers as their performance which contributed to their company. There are many types of compensations, such as salaries, wages, incentives, benefits, services, good physical working conditions, facilities, etc. Those are kinds of compensations which can't be viewed as responsibility or reciprocal payments to the workers' performance, but also something which can motivate them to achieve better than others.

Performance evaluation is one form of extrinsic motivation. Performance evaluation is a process to assess the workers' performance which can give feedback to reach optimum work and organizational performance. Effective performance evaluation will motivate the evaluated workers through give information about the lack of competency which must be reduced, the superior competency which must be maintained and sustained, and the efforts which must done by the workers to achieve great performance. The "fruit" of performance evaluation is more enhanced competent workers. Performance evaluation leads the workers to become "real workers" who aware about their competency, want to increase the insufficiency of demanded competency by the company, and show the best performance from time after time in their organization. Based on Maslow Motivation Theory, the highest needs of human are self-actualization. Performance evaluation will motivate the workers to 
actualize their ability in show optimum performance, which end in satisfaction and pride of the workers toward themselves. This condition can be called by "cyclical motivation function" through performance evaluation, motivation creates motivation.

The company should set a wiser compensation policy. The Indonesian company should give every types of compensation to contractual workers as fixed workers; but of course the amount of it surely won't be same with the fixed one. With this compensation policy, contractual workers will felt appreciated by the company. This is called a fairness or equity of compensations perceived by the workers. The contractual workers will feel that they existence regarded as important as the fixed workers. Contractual workers will feel comfortable, they will perceived this company compensation policy as the company trait which reflected that all workers, both fixed and contractual workers have the same rights as the big family of the company. In long term, this "equal compensation system" expected can anticipate the coming of job insecurity among contractual workers. Indonesian company also can motivate the contractual workers by set regular performance appraisal. Contractual workers should evaluate their performance in certain times. The company should consider the performance besides the bound of contract time between the company and contractual workers. The company shouldn't only assess the fixed workers' performance, but also contractual workers. The company should provide opportunity for contractual workers to show great performance; so that, the company could consider them to lengthens the contract working period. Further, the company could change the status of contractual workers from contractual to the fixed one. With this policy, the contractual workers can be motivated to show great performance and compete with fixed workers, in equal time and rights. Job insecurity among contractual workers can be pushed down as strong as possible with performance appraisal towards contractual workers.

The similar things will be happened in outsourcing, but the object is different. If in contractual workers, job insecurity felt by themselves; but in outsourcing, job insecurity knocks over fixed workers from the company who apply outsourcing. Indonesian company should keep the certain amount of compensation as the fixed workers' rights. Of course, the outsourced workers who regarded by the company as the specialized skill manpower, shouldn't give special or extra compensation which higher than given to the fixed workers. The fixed workers will think and feel that the company still acknowledges them as main human power in the company before outsourced workers. In long term, this compensation treatment expected can anticipate the coming of job insecurity among fixed workers. Performance evaluation toward existing fixed workers can motivated them to showing better performance rather than the outsourced workers. The company who conduct outsourcing will have two types of workers, existing fixed workers and outsourced workers. The company 
will assess the performance of these both workers and could be compare them. Performance evaluation should motivate the existing fixed workers through "invisible competition" between existing fixed workers and outsourced workers. If the performance of existing fixed workers is higher than the outsourced workers, the company will prioritize the existing fixed workers. Next, this situation will makes the existing fixed workers feel "safe" meaning that they have more value added to the company and automatically the company will maintain them in the company for the long term because of their achievement. Thus, performance evaluation can anticipate and reduce the emergence of job insecurity among existing fixed workers.

In mergers-acquisitions, job insecurity can be happened in all workers in the company which probably conduct it. The effect of compensation to anticipate job insecurity among workers won't be as significant as outsourcing; because if layoffs are conducted by the company, the workers will lose their compensation totally, they only get allowance of involuntary retirement. Performance evaluation can be used as better way to motivate the workers which can decrease job insecurity. Performance evaluation can be regarded as filters for all workers in the company. The company can measure the performance of the workers and use the result of it as the consideration to decide whether workers are deserve to be still employed and whether aren't deserved anymore to be employed in the company. Performance evaluation can be functioning as stimulation tools to makes the workers' performance better in order to survive in the company. Performance evaluation can motivate the workers to enhance their motivation in peak performance. The workers with great performance will have "internal and external safe", meaning that the excellent workers will believe that the company will employed them. Also, even if the company have itself consideration (such as because mergers-acquisitions) and still "cut" the working relationship between the workers and the company; the workers will be sure that they can get another jobs and works in others company. Performance evaluation provides the way to motivate the workers to showing great performance and if this condition continues in the long term, the occurrence possibility of job insecurity will be reduced and anticipated.

Finally, through motivation function, the workers will have individual rapid individual awareness and intent to perform the best for the company. It means that by motivate them, the workers will lead to the fact that to survive in the company, they must "fight" with the issues: outsourcing, mergers-acquisitions, and contractual workers; in form of promote themselves with great working performance. Also, if this circumstance happened in the long term continually; the workers can be turned to "star workers" who have strong enough ability which can compete with others, especially external workers. These two conditions will reduce job insecurity of workers and also increased job security, confidence of the workers about 
their working future conditions. Reversely, job insecurity changed to job security, means that the workers can work well in every challenge in every company which will face them with any strategies and abilities demand as natural selection. Job insecurity as "the product" of outsourcing, mergers-acquisitions, and contractual workers can be minimized and solved by compensation as extrinsic motivation functions; and performance evaluation as intrinsic motivation.

Based on a conceptual analysis, the author has an argument that those issues: outsourcing, mergers-acquisitions, and contractual workers have positive impact on job insecurity. It means that if the company use the outsource workers; conduct mergersacquisition strategy, and use the contractual workers, this situation can cause and further increase job insecurity among workers. A recommendation which gave by the authors is use motivation function to solve or decrease job insecurity. In the other word, motivation function has negative impact on job insecurity. Further, motivation function can moderate the impact of outsourcing, mergers-acquisitions, and contractual workers on job insecurity. Moderate mean that the variable (motivation function) can increase or decrease the impact, in this situation motivation function can decrease the impact of outsourcing, mergers-acquisitions, and contractual workers on job insecurity. Based on the reason which the authors said on the previous explanation, the authors give a recommendation to the future research. Because outsourcing, mergers-acquisitions, and contractual workers conceptually have positive impact on job insecurity, and motivation function can decrease the impact of those issues on job insecurity. So, many researchers can conduct the research which tests the effect of outsourcing, mergers-acquisitions, and contractual workers on job insecurity with moderated by motivation function. The model of this study can describe on the exhibit below.

Exhibit 1

The effect of outsourcing, mergers-acquisitions, and contractual workers On job insecurity with moderated by motivation function

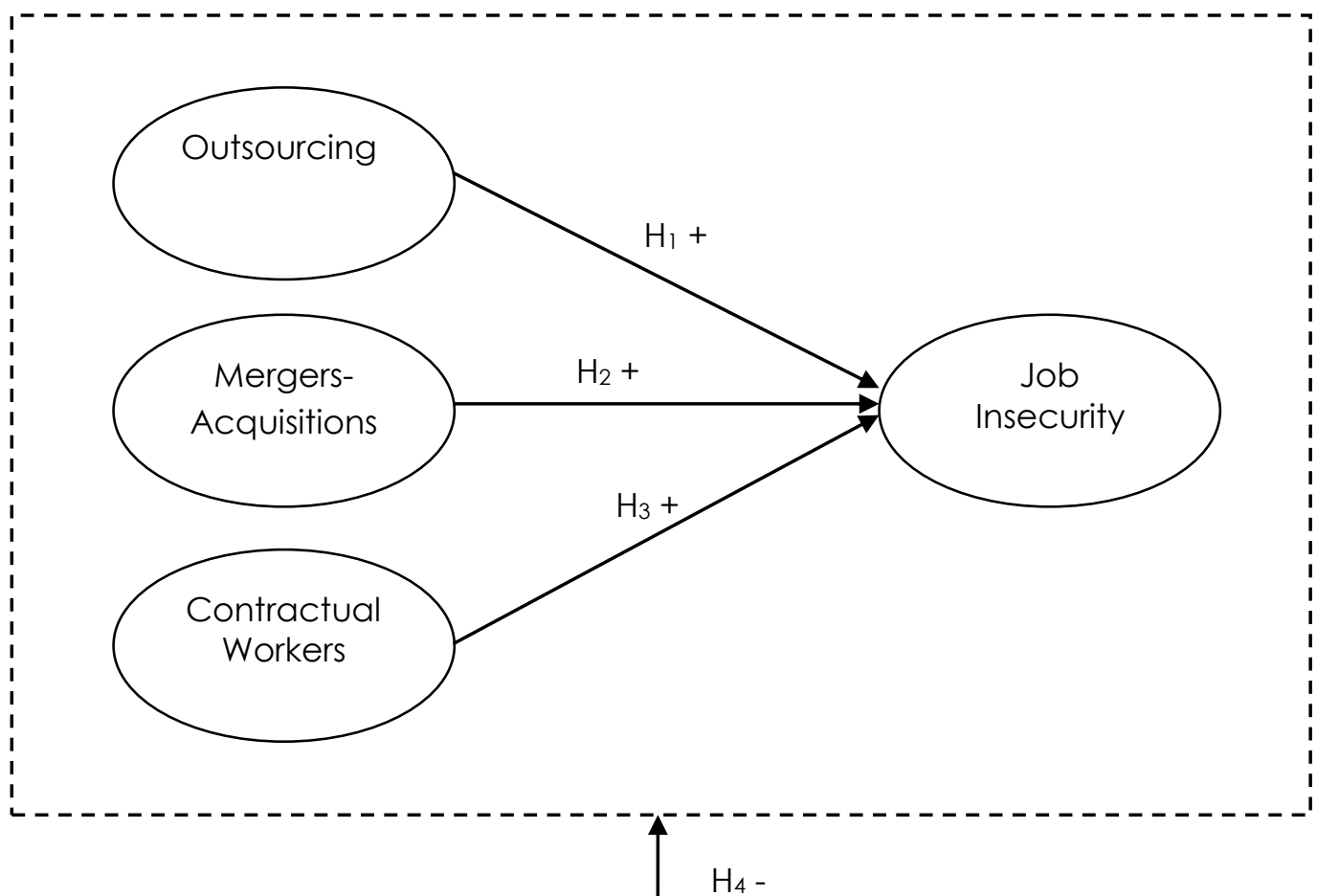




\section{REFERENCES}

Cooper, C.L. 2006, "The challenges of managing the changing nature of workplace stress", Journal of Public Mental Health, vol. 4, pp. 6.

Davy, J.A; Kinicki, A; Kilroy, J; Scheck, C. 1988, "After the Merger: Dealing with People's Uncertainty", Training and Development Journal, no. 42, pp. 57.

Guest, D. and Clinton, M. 2006, "Temporary Employment Contracts, Workers' Well-Being and Behavior: Evidence from the UK", Department of Management King's College, no.38, pp. 1-33.

Robbin, S.P. and Judge, T.A. 2007, Organizational Behavior, Pearson Education Inc., New Jersey.

Setiawan, R. 2008, "Trends and Issues in Human Resource Management in Indonesia", unpublished.

Setiawan, R. 2008, "Dampak job insecurity di dalam hubungan ketenagakerjaan", unpublished.

Setiawan, R. and Hadianto, B. 2008, "Job insecurity dalam organisasi", unpublished.

http://www. wikipedia.com 
http://www.tempointeraktif.com/hg/nasional/2003/06/25/brk,20030625-03,id.html.

http://www.kapanlagi.com/h/0000079586.html.

http://www.PortalHR.com

http://www.swa.co.id 